\title{
Stress in Pregnancy: A Role for Neuroactive Steroids in Protecting the Fetal and Neonatal Brain
}

\author{
Jonathan J. Hirst ${ }^{\mathrm{a}}$ David W. Walker ${ }^{\mathrm{b}}$ Tamara Yawno $^{\mathrm{b}}$ Hannah K. Palliser ${ }^{\mathrm{a}}$ \\ aSchool of Biomedical Sciences, University of Newcastle, Callaghan, N.S.W., and bepartment of Physiology, \\ Monash University, Clayton, Vic., Australia
}

\section{Key Words}

Stress in pregnancy $\cdot$ Pregnancy compromise $\cdot$ Neuroactive steroids $\cdot$ Allopregnanolone $\cdot$ Neuroprotection $\cdot$ Placenta

\begin{abstract}
Stressors during pregnancy can lead to perinatal brain injury resulting in serious neurological impairment. Neuroactive steroid concentrations are elevated during pregnancy and are remarkably high in the fetal brain. In long-gestation species, including humans, these steroids enhance GABAergic inhibition and reduce the possibility of cerebral excitotoxicity during the last third of gestation. The fetal brain responds to acute hypoxia/ischemia by increasing steroid concentrations further as protection against excitotoxic cell death. The placenta has a key role in maintaining neuroactive steroid concentrations in the brain by acting as a source of precursors for neuroactive steroid synthesis. Gestational neuroactive steroid concentrations are needed for normal cell proliferation and cell death in the late gestation brain and a loss of these steroids at preterm birth may adversely affect development and vulnerability to injury.
\end{abstract}

Copyright $\odot 2009$ S. Karger AG, Basel

\section{Introduction}

Compromised pregnancies can have serious effects on the fetal brain, the nature of which depends, in large part, on the time during gestation when they occur. Maternal stress, infection, or problems with placentation can affect brain development due to changes in the delivery of oxygen and glucose to the brain, or the cytokine environment, leading to acute cell death, particularly in vulnerable regions such as periventricular white matter, the hippocampus and the cerebellum [Inder et al., 1999; du Plessis and Volpe, 2002]. Certain glial progenitor cells are highly susceptible to such insults. In addition, chronically suboptimal conditions during pregnancy dramatically increase the sensitivity of the fetal brain to further episodes of hypoxia/ischemia around the time of birth and in the immediate neonatal period. The resulting damage can lead to severe neuropathology including intellectual impairment and cerebral palsy [Inder et al., 1999]. More subtle damage has been shown to reduce performance when children reach school age and to lead to behavioral and social disorders in later life. In this review, we examine the evidence that the steroid environment of pregnancy helps to protect the fetal brain from compromise, as well as aiding the repair of damage caused by acute insults [Yawno et al., 2007b]. These actions are

E-Mail jon.hirst@newcastle.edu.au 
largely mediated by the positive modulation of $\mathrm{GABA}_{\mathrm{A}}$ receptors and the enhancement of GABAergic inhibitory neurotransmission [Belelli et al., 2006]. The $5 \alpha$-reduced progesterone metabolites such as allopregnanolone $(5 \alpha-$ pregnane-3 $\alpha$-ol-20-one) are potent agonists of the GAB$A_{A}$ receptor and appear to be of great importance in modulating excitability in the maternal and fetal brain.

In adult animals, the steroid environment of the brain is at least partially controlled by steroidogenesis within brain tissue [Baulieu, 1997]. The term neurosteroid has been used to refer to steroids synthesized de novo from cholesterol in the nervous system or alternatively when the last step(s) in synthesis take(s) place in the nervous system. In pregnancy, a large proportion of the production of steroids that affect the fetal nervous system are derived from peripheral sources. Therefore, we have used the term neuroactive steroids to refer to steroids that influence fetal or maternal nervous system function and may be synthesized both in the nervous system and/or other peripheral organs. Key studies have demonstrated the independent control of production of neuroactive steroids, including allopregnanolone, by rate-limiting synthesis steps occurring in the CNS, but with peripheral steroidogenesis providing precursors. Thus, differences in the supply of these precursors including progesterone from the corpus luteum contribute to the variation of neuroactive steroid levels seen during the estrous cycle; for example in both the plasma of women during the menstrual cycle and in the rat brain [Baulieu, 1997; Bixo et al., 1997].

In pregnancy, the placenta of long-gestation species is a source of massive amounts of progesterone that enter not only the maternal circulation, but also fetal blood and the fetal brain, where it is actively converted into the $\mathrm{GABA}_{\mathrm{A}}$ receptor active pregnane steroid, allopregnanolone [Crossley et al., 1997]. Indeed, the level of allopregnanolone in the fetal sheep brain far exceeds that found in the postnatal and adult brain [Nguyen et al., 2003b], and the interaction with the $\mathrm{GABA}_{\mathrm{A}}$ receptor is correspondingly greater and sufficient to suppress fetal CNS activity in late gestation [Nicol et al., 1998, 1999]. Allopregnanolone is present in sufficient quantity to effectively raise the threshold for excitotoxicity in the fetal brain, as shown by the fact that severe fetal hypoxia produces greater damage when synthesis of allopregnanolone is suppressed [Yawno et al., 2007b]. More recent studies suggest that progesterone metabolites also have a role in development and repair of the fetal brain after exposure to hypoxia and other potential stressors in late pregnancy.

\section{Action of Allopregnanolone on the Fetal Brain}

When determining the role of $\mathrm{GABA}_{\mathrm{A}}$ receptor agonist and antagonist neuroactive steroids it is essential to consider timing of brain development and stage of gestation. In long-gestation species such as the human, sheep and guinea pigs much brain development occurs before birth. In these species, GABAergic currents are inhibitory by the last third of gestation. Hence, the often-quoted advice that $\mathrm{GABA}_{\mathrm{A}}$ receptors are excitatory in the developing brain, while true for the fetus and neonate of altricial species such as the mouse and rat [Kellogg, 1988], is somewhat less relevant for long-gestation species, including the human, where pregnancy is long enough for considerable brain development to have been achieved before birth occurs. To evaluate the potential effects of neuroactive steroids on the human perinatal brain and the likely effect of preterm birth, it is essential to use species with long gestations and which deliver relatively mature neonate. We have reported a marked increase in excitability in the fetus with infusion of the $\mathrm{GABA}_{\mathrm{A}}$ receptor channel blocker picrotoxin in the late-gestation fetal sheep [Nicol et al., 1999]. This picrotoxin-induced activity was blocked by allopregnanolone treatment as early as 110 days of gestation in the sheep (term 148 days). These data show that functional, inhibitory GABA receptors are present by 0.7 gestation in this species, and that GABA receptor function is readily modulated by steroids at a $\mathrm{GABA}_{\mathrm{A}}$ receptor binding site. We have further shown that $\mathrm{GABA}_{\mathrm{A}}$ receptor expression increases from 100 days (0.67) of gestation in the sheep, reaching a level of expression equivalent to that of adult sheep by 125 days; i.e., by 0.84 of gestation. These receptors are sensitive to allopregnanolone in the 100 nanomolar-micromolar range in vitro (fig. 1a). Strong allopregnanolone binding is observed throughout the fetal brain at this gestational age (fig. 1b) [Crossley et al., 2000]. The concentration of allopregnanolone required to displace an antagonist from the $\mathrm{GABA}_{\mathrm{A}}$ receptor in vitro is thus somewhat above the range we have measured in fetal sheep brain homogenates throughout late gestation [Nguyen et al., 2003b]. However, potentially higher local concentrations could interact with $\mathrm{GABA}_{\mathrm{A}}$ receptors to enhance GABAergic activity. These findings suggest that local synthesis of allopregnanolone and related neuroactive steroids exert a major inhibitory effect on the fetal brain. 
a

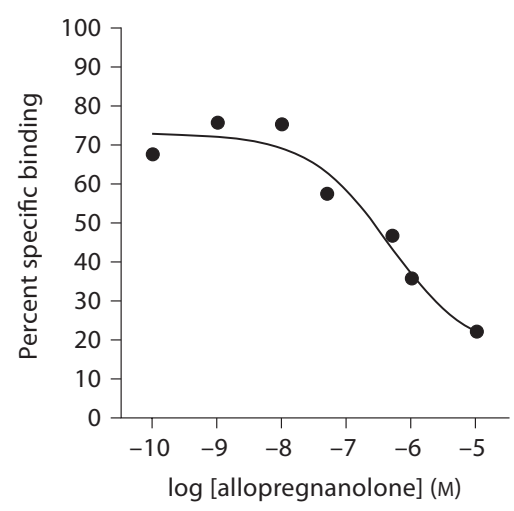

Fig. 1. a Concentration-dependent inhibition of the binding of the $\mathrm{GABA}_{\mathrm{A}}$ receptor antagonist $\left[{ }^{35} \mathrm{~S}\right]$-TBPS by allopregnanolone. $\mathrm{GABA}_{\mathrm{A}}$ receptor preparations were from fetal sheep frontal cortex homogenates at 145 days of gestation. b Autoradiographs of the fetal frontal cortex show displacement of $\left[{ }^{35} \mathrm{~S}\right]$-TBPS binding to $\mathrm{GABA}_{\mathrm{A}}$ receptors by allopregnanolone. (1) Total $\left[{ }^{35} \mathrm{~S}\right]-\mathrm{TBPS}$ binding; (2) binding in the presence of allopregnanolone $(200$ $\mathrm{nM})$; (3) nonspecific binding in the presence of picrotoxin (100 $\mu \mathrm{M})$. Cd-Put = Caudate putamen; layers I-VI = cortical layers I-VI. b
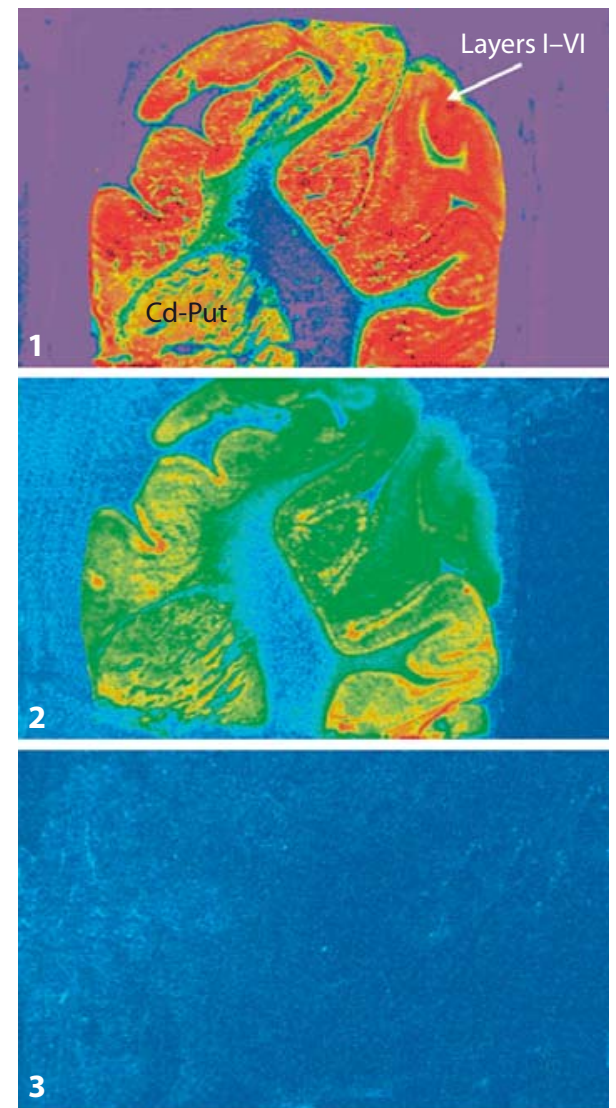

\section{Neuroactive Steroid Concentrations in the Fetal and Maternal Circulations}

Progesterone production by the placenta increases during pregnancy in long-gestation species including humans, and leads to increased availability of precursors for neuroactive steroid production [Conley and Mason, 1990; Smith, 2007]. For example, Hill et al. [2007] investigated the concentration of free progesterone metabolites and their sulfated derivatives in the maternal circulation, and reported the presence of high concentrations of $5 \alpha$ - and $3 \alpha$-reduced progesterone metabolites during pregnancy. Placental synthesis results in plasma levels in excess of those required to stimulate progesterone receptors (PR) in reproductive tissue, but this may ensure that precursors are available for neuroactive steroid production by the fetal brain. Earlier studies in sheep have shown that a large amount of placental progesterone production is metabolized in the placenta itself [Dolling and Seamark, 1979]. This results in the release of a relatively low proportion of $\mathrm{GABA}_{\mathrm{A}}$ receptor active metabolites as well as a relatively large amount of metabolites that can be pre- cursors for neuroactive steroid production in the brain. In addition, several $3 \beta$-reduced pregnane steroids are produced [Dolling and Seamark, 1979] and while little is known regarding the control of the relative production of these steroids by the placenta, more recent studies have also found considerable amounts of $3 \beta$-reduced steroids in the maternal circulation [Bicikova et al., 2002; Hill et al., 2007]. This is consistent with the presence of both $3 \beta-$ reductases and $5 \alpha$-reductases in the placenta. These steroids have little agonist action at the $\mathrm{GABA}_{\mathrm{A}}$ receptor and some may be antagonists although their contribution in modulating GABAergic transmission remains unclear [Harrison et al., 1987]. In addition, many potentially neuroactive metabolites are present in the circulation as sulfated esters [Bicikova et al., 2002]. Sulfated steroids cross the blood-brain barrier very slowly and so are unlikely to influence the maternal brain. The fetus has a functional blood-brain barrier by the beginning of the last third of gestation in sheep and humans, and so the passage of steroid sulfates into the brain would also be expected to be limited after this time [Saunders et al., 2000]. As these steroids can be readily desulfated by sulfatase activity, it 
Fig. 2. Effect of $3 \beta$-hydroxysteroid dehydrogenase inhibition by trilostane treatment (open bars) and progesterone replacement (black bars) on the proportion of recording time occupied by markers of behavioral activity in the fetal sheep. LV ECoG = Low-voltage electrocorticographic activity; EOG = electro-ocular activity; Nuchal EMG = nuchal muscle electromyographic activity; $\mathrm{FBM}=$ fetal breathing movements; Arousal $=$ fetal arousal activity that was defined as the presence of nuchal EMG activity observed concurrently with ECoG activity in the LV state. Groups of fetuses $(n=6)$ received either trilostane or trilostane and progesterone during late gestation (135-137 days of gestation). Values are means of the proportion of time occupied by arousal-like activity during 2hour recording epochs, as a proportion of the basal pretreatment levels ( \pm SEM). The asterisk indicates significant difference between trilostane treatment and progesterone replacement $(\mathrm{p}<0.05)$.

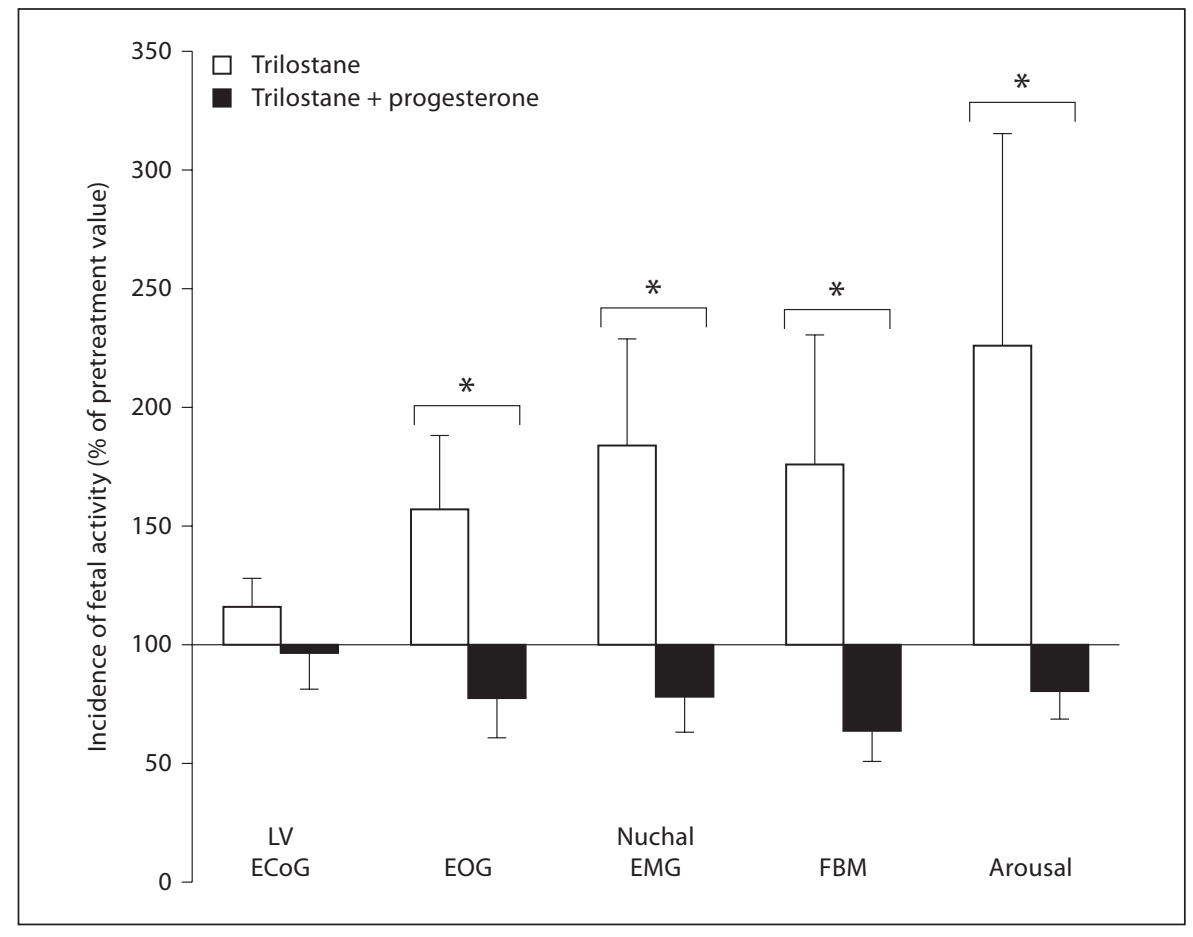

can be speculated that they could act as a reserve pool of pregnane steroids, and perhaps minimize fluctuations arising from variations due to changes of placental function; however, further studies are required.

\section{Neuroactive Steroids and Behavior during Pregnancy}

\section{Maternal}

Evidence from animal studies indicate that elevated neuroactive steroid levels in pregnancy suppress excitability and increase lethargy [Paoletti et al., 2006]. This is consistent with the elevated plasma levels of $\mathrm{GABA}_{\mathrm{A}}$ receptor agonist steroids reported in women during pregnancy [Hill et al., 2007]. These changes are lost at birth with the removal of the placenta suggesting that placental progesterone production is mostly responsible for the elevated neuroactive steroid levels in the plasma and their reported effects on mood [Nappi et al., 2001; Gilbert Evans et al., 2005]. However, little is known about the quantitative contribution of the placenta to neuroactive steroids in the maternal brain. Reductases in the brain may have a gate-keeping role during pregnancy limiting the conversion of steroids to $\mathrm{GABA}_{\mathrm{A}}$ receptor active derivatives, but the drop in neuroactive steroid levels in plasma of women at parturition is consistent with the placenta having a major influence over maternal behavior [Nappi et al., 2001]. The postpartum fall in neuroactive steroid concentrations has been connected with depressive illness after birth; however, such a relationship is more complex as neuroactive steroids decline rapidly after birth whereas these conditions appear to develop more slowly [Harris et al., 1996; Bloch et al., 2003]. Further study of the contribution of the return of ovarian function and the potential role of adrenal steroidogenesis in postpartum behavior and mood is required.

\section{Fetal}

The developing fetus is profoundly affected by the neuroactive steroid environment, and thus by the placenta (fig. 2). We were first to show that fetal activity and behavior in utero is markedly influenced by placental steroidogenesis [Crossley et al., 1997]. Both the human and sheep fetus show short-term cyclic changes in brain activity during the last third of gestation that have been interpreted as sleep-like behaviors and direct recording of the EEG of fetal sheep confirms the emergence of REM and nonREM-like sleep states [Clewlow et al., 1983; Szeto, 1992]. These sleep-like states are interrupted periodically by very short episodes of activity that are similar to arousal patterns seen in the adult [Szeto, 1992]. The incidence of 
this arousal-like activity is low during fetal life, suggesting that the fetus may have a high threshold to sensory stimulation and/or that the fetal CNS is under some form of tonic suppression [Nicol et al., 2001]. We showed that suppression of placental progesterone production with a $3 \beta$ hydroxysteroid dehydrogenase inhibitor leads to a marked rise in the level of fetal arousal-like activity and a fall in the amount of REM-sleep-like activity (fig. 2). Importantly, these increases were returned to normal fetal levels by co-infusion of progesterone that returned progesterone concentrations to typical maternal gestational plasma levels [Crossley et al., 1997]. These findings show that the fetal arousal is suppressed by steroids, most likely progesterone derived from the placenta. Fetal arousal also increases when $5 \alpha$-reductase activity is blocked by direct infusion of finasteride into the sheep fetus [Nicol et al., 2001]. In addition, finasteride treatment increased the sensitivity of the fetal brain to sensory stimulation; i.e., the excitability of the fetal CNS was increased. Together, these findings indicate that $5 \alpha$-reduced progesterone metabolites, particularly allopregnanolone, are important in maintaining a suppressed fetal behavioral state during late gestation, and that placental progesterone production is important in maintaining the allopregnanolone levels present in fetal blood and the brain.

It has been suggested that REM sleep is important for brain development [Richardson, 1992], and it is possible that premature loss of the placental source of progesterone, such as will occur with preterm birth, could have the effect of disturbing the normal course of brain development over the final weeks of pregnancy. As one action of allopregnanolone is to increase the incidence of REM sleep, neuroactive steroid-dependent mechanisms might be important for maintaining fetal behavior appropriate for normal brain development. Hence the fall in allopregnanolone concentrations following preterm birth may have serious consequences for brain development and normal function in the neonate.

\section{Neuroactive Steroid Synthesis in the Placenta and Fetal Brain}

The importance of 'de novo' synthesis within the fetal brain and the supply of placental precursors to the high concentrations of neuroactive steroids observed during fetal life remains unclear. Indeed, the relative contribution of 'de novo' synthesis within the developing brain and the placenta may change with advancing gestation. The key enzymes required for the synthesis of progesterone and its metabolism to allopregnanolone are present in the fetal brain. P450 cholesterol side chain cleavage enzyme (P450scc), which catalyses the formation of pregnenolone from cholesterol, is expressed strongly in the fetal sheep brain throughout the second half of gestation [Nguyen et al., 2003b]. However, the concentrations of pregnenolone and progesterone in the brain decline markedly at birth, suggesting that brain synthesis from cholesterol was not sufficient to account for the levels of these steroids found in the fetal brain, and a peripheral source such as the placenta is required to maintain these concentrations during fetal life. $3 \beta$-Hydroxysteroid dehydrogenase, which is required for the conversion of pregnenolone to progesterone, is also expressed in the brain [Martini et al., 1996] suggesting that pregnenolone, provided from any source (brain, adrenal, placenta), will contribute to neuroactive steroid production in the brain [Zwain and Yen, 1999]. Pregnenolone produced by the placenta is rapidly and efficiently converted to pregnenolone sulfate in the fetal circulation [McKay, 1987], and although pregnenolone sulfate has a $\mathrm{GABA}_{\mathrm{A}}$ receptor antagonist action and may reduce the effectiveness of allopregnanolone, its access to the brain is restricted by the presence of a blood-brain barrier in late gestation [Saunders et al., 2000]. However, certain stressors such as intrauterine infection can reduce the effectiveness of the fetal blood-brain barrier [Yan et al., 2004], and in such conditions pregnenolone sulfate may enter the neuropil and increase excitatory damage, even if the pregnenolone itself can potentially act as a precursor for further allopregnanolone production [Weaver et al., 1998]. Thus the effects of pregnenolone sulfate on the developing brain may be very important, although lack of experimental evidence renders this point uncertain. Furthermore, the presence of contaminating nonpolar substances in brain extracts has made quantification difficult [Liere et al., 2004] and recent analysis indicates that only very low levels of pregnenolone sulfate are present in adult rodent brain [Schumacher et al., 2008].

The metabolism of progesterone to allopregnanolone requires both $5 \alpha$ - and $3 \alpha$-reduction by the enzymes $5 \alpha-$ reductase and $3 \alpha$-hydroxysteroid oxidoreductase, respectively. $5 \alpha$-Reductase irreversibly converts progesterone to $5 \alpha$-dihydroprogesterone and is the key regulatory step in the synthesis of $\mathrm{GABA}_{\mathrm{A}}$ receptor agonist steroids. There are two isoforms of $5 \alpha$-reductase, type 1 and type 2. The $5 \alpha$-reductase 2 isoform is expressed in the rat brain [Martini et al., 1996], and we have found that this is expressed strongly in the fetal sheep brain from the second half of gestation [Nguyen et al., 2003a]. We further found that $5 \alpha$-reductase 2 expression increases in 
Fig. 3. Schematic diagram showing the potential contributors to allopregnanolone concentrations in the fetal brain during late gestation and indicates the passage of placental steroid to the brain. $5 \alpha-\mathrm{R} 1 / 2=$ $5 \alpha$-Reductases 1 and/or 2; $5 \alpha$-DHP $=5 \alpha$ dihydroprogesterone.

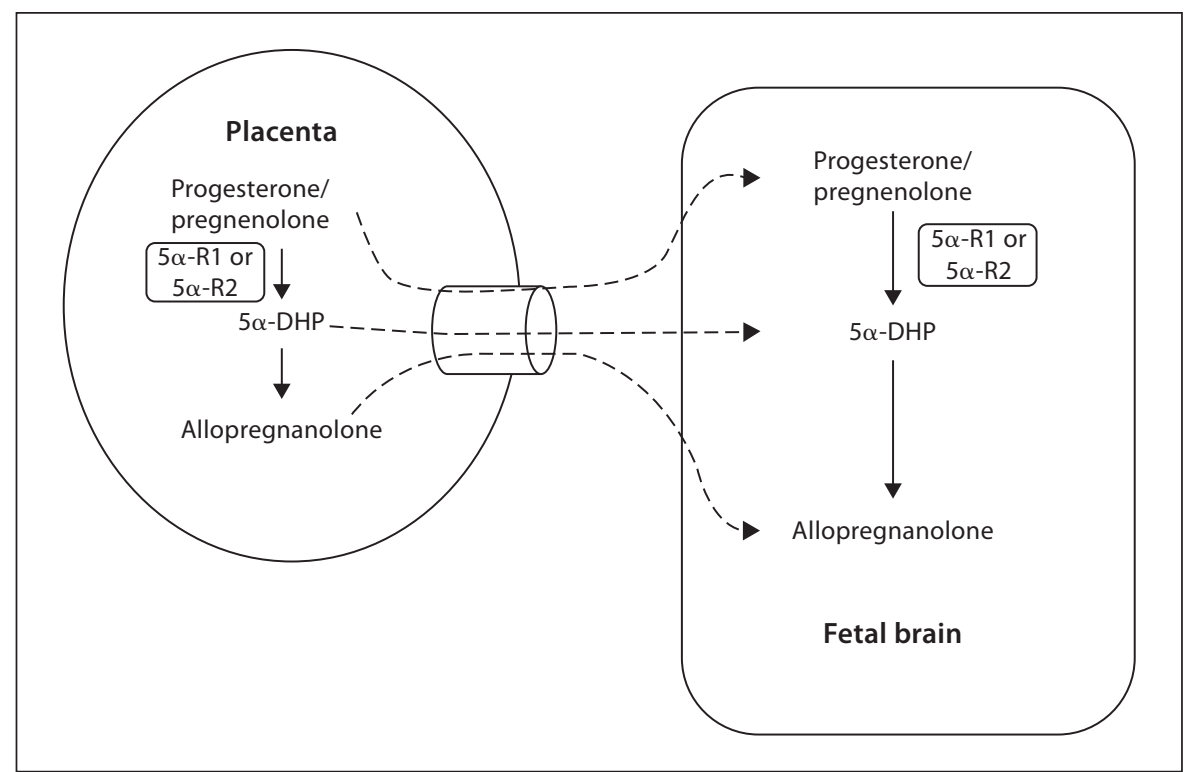

parallel with allopregnanolone levels in the fetal brain suggesting that this isoform may have a major role in the control of allopregnanolone levels. These data are consistent with the marked excitatory effect of finasteride - an inhibitor of $5 \alpha$-reductase 2 activity - on fetal CNS activity mentioned earlier [Nicol et al., 2001], and supports the contention that this treatment acts on the fetus by suppressing allopregnanolone levels in the brain. $3 \alpha-\mathrm{Hy}-$ droxysteroid oxidoreductase is required for the final step in allopregnanolone production. Studies in rats suggest this enzyme has a wide distribution in neurons and glia, but little is known about the levels of this enzyme in the brain of fetuses of long-gestation species, such as the sheep and human. The marked effect of finasteride on the sheep fetus, however, suggests that $5 \alpha$-reductase activity is rate-limiting and controls the availability of allopregnanolone in the fetal brain.

Overall, our studies support the concept that the placenta supplies progesterone and possibly pregnenolone to the fetal circulation, and that these steroids are converted to allopregnanolone within the brain (fig. 3). This is consistent with findings in the late-gestation fetal sheep indicating that concentration of allopregnanolone in the brain is somewhat independent of that in the fetal circulation [Nguyen et al., 2004a]. There is considerable evidence showing $5 \alpha$-reductase activity in the human placenta [Milewich et al., 1979, 1987], and the expression of both $5 \alpha$-reductase 1 and 2 isoenzymes increases toward term [Vu et al., 2009]. The placenta may also be an im- portant source of allopregnanolone for the brain (fig. 3), at least for determining basal levels that are then augmented by increased $5 \alpha$-reductase activity in response to hypoxic or inflammatory stresses (fig. 4). In addition to $5 \alpha$-reductases, Sheehan et al. [2005] have reported $5 \beta$-reductase expression in the human placenta as well as in other intrauterine tissues. This enzyme may therefore contribute to $5 \beta$-dihyrodprogesterone found in the maternal circulation and may also account for some of the $5 \beta$-reduced progesterone metabolites in the fetal circulation. Although the role of these metabolites in the fetus is unclear, the $5 \beta$ - and $3 \alpha$-hydroxy derivatives are agonists at the $\mathrm{GABA}_{\mathrm{A}}$ receptor and could influence excitability [Harrison et al., 1987]. Expression of $5 \beta$-reductase was shown to fall near term whereas $5 \alpha$-reductase expression was found to be increased [Vu et al., 2009]. Thus, a potential change in the contribution of these enzymes to neuroactive steroid synthesis may occur near term [Sheehan et al., 2005]. Further investigation of the role of these changes in the fetus is warranted.

\section{Stressor-Induced Changes in Allopregnanolone Concentrations and Neurosteroidogenic Enzyme Expression}

Considerable evidence now indicates that progesterone protects the brain following traumatic brain injury, and that this involves the metabolism of progesterone to 


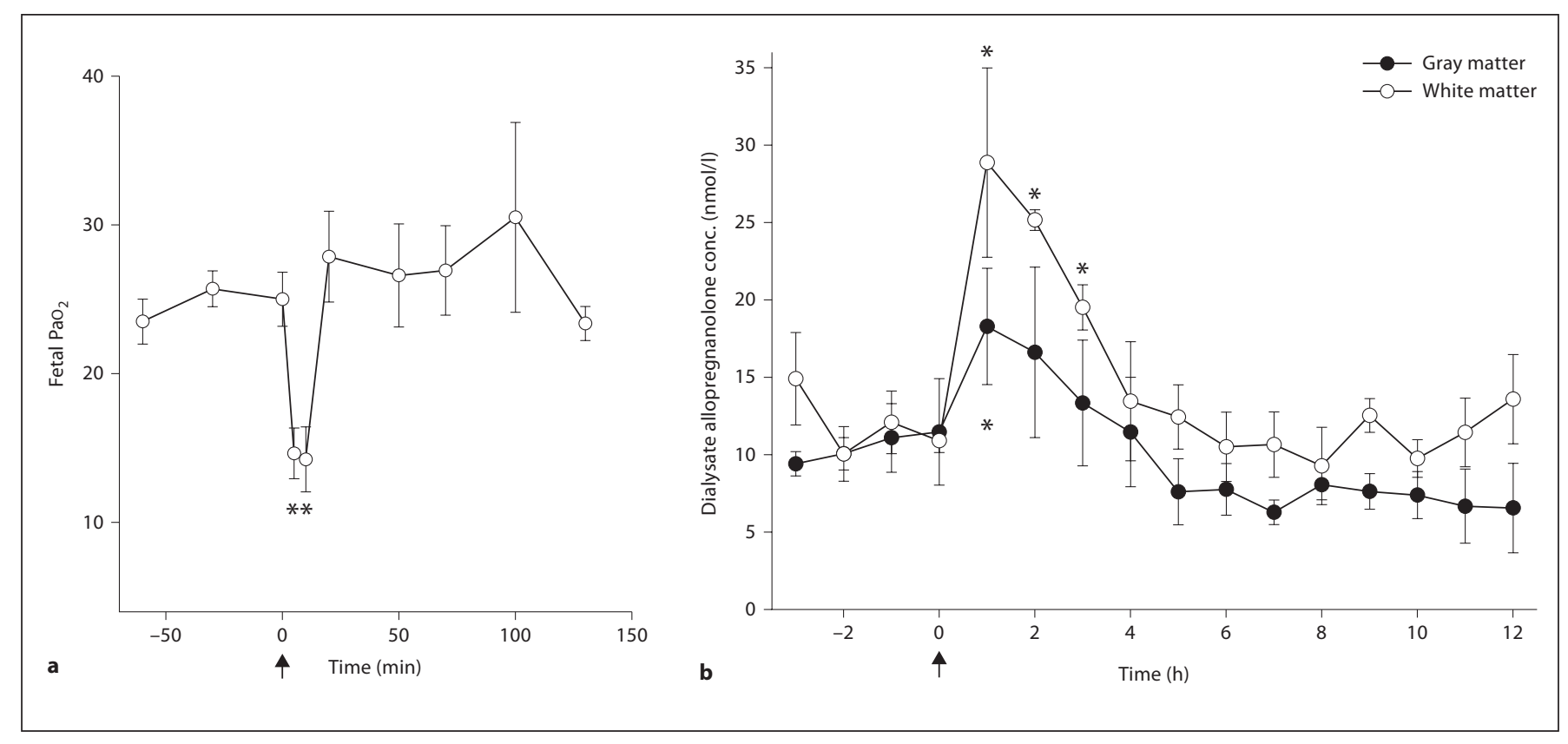

Fig. 4. Effect of the 10-min umbilical cord occlusion on fetal arterial partial pressure $\left(\mathrm{PaO}_{2}\right)(\mathbf{a})$ and allopregnanolone concentrations in fetal brain gray (closed circles) and white matter (open circles) (b). Horizontal axis shows time relative to the 10-min umbilical cord occlusion (time 0 , arrow). $\mathrm{PaO}_{2}$ was significantly depressed during and immediately after the occlusion, but rapidly returned to pre-occlusion levels. Allopregnanolone concentration in microdialysis probe outflow was increased in both gray and white matter after the occlusion and levels in white matter remained elevated for $3 \mathrm{~h}$. The asterisk indicates a significant $(\mathrm{p}<0.05)$ difference compared to pre-occlusion control values $\pm \operatorname{SEM}(\mathrm{n}=4)$.
$\mathrm{GABA}_{\mathrm{A}}$ receptor agonists such as allopregnanolone [Djebaili et al., 2005]. In addition, evidence is growing that progesterone reduces the area of damage after ischemic stroke both in animal models and in human trials [Stein, 2008]. Structural and functional differences in maturity of glia and neurons in the CNS of the developing fetus lead to a high vulnerability to brain damage associated with excessive excitation [McLean and Ferriero, 2004]. Immature oligodendrocytes and neurons are highly vulnerable to hypoxic challenges [Back et al., 2002]. To determine if neuroactive steroid synthesis can help to reduce excitotoxic brain damage, we examined the effect of acute fetal hypoxia/ischemia induced by occluding the umbilical cord of fetal sheep for $10 \mathrm{~min}$ in late gestation; allopregnanolone concentrations were continuously sampled from probes implanted in the gray and white matter regions of the brain [Nguyen et al., 2004b]. Cord occlusion resulted in a dramatic fall in arterial partial pressure of $\mathrm{O}_{2}\left(\mathrm{PaO}_{2}\right.$; fig. 4), $\mathrm{O}_{2}$ saturation and $\mathrm{pH}$ as well as a rise in arterial partial pressure of $\mathrm{CO}_{2}\left(\mathrm{PaCO}_{2}\right)$. This type of acute hypoxia causes marked cell death in the hippocampus and other vulnerable areas of the fetal brain
[Castillo-Melendez et al., 2004]. As shown in figure 4 [Nguyen et al., 2004b], there was a marked increase in allopregnanolone concentrations observed in both the gray and white matters following this acutely imposed hypoxia, a response that continued for at least $2-3 \mathrm{~h}$ after the hypoxia was over. These findings show that neuroactive steroid synthesis in the fetal brain can respond rapidly to hypoxic stress, much like that observed in the adult brain after acute stress [Barbaccia et al., 1996].

While progesterone and its pregnane metabolites appear to reduce excitotoxicity, progesterone may also stimulate repair processes [Stein, 2008]. The relatively high white matter content of the human brain, compared to other species, results in white matter damage making a major contribution to ischemic injury both in the adult and the fetus [Inder and Volpe, 2000; Frisk et al., 2002; Luciana, 2003; Schumacher et al., 2007]. As progesterone has been shown to stimulate myelination, these findings suggest that progesterone and/or some of the metabolites may reduce white matter injury following perinatal hypoxic/ischemic episodes. The finding of increased allopregnanolone concentrations in white matter following 
Fig. 5. Photomicrograph showing activated caspase-3-immunoreactive cells in the hippocampus (CA3) of fetal sheep that received vehicle infusion alone (a), vehicle infusion and 5-min cord occlusion (b), finasteride infusion and 5-min cord occlusion (c), and finasteride infusion alone (d). Finasteride or vehicle infusion commenced $30 \mathrm{~min}$ prior to the 5 -min period of umbilical cord occlusion and lasted for $2 \mathrm{~h}$, at 131-133 days of gestation. Tissues were collected $24 \mathrm{~h}$ after the umbilical cord occlusion, or at an equivalent time for the fetuses that did not undergo the occlusion procedure. Umbilical cord occlusion caused a rise in the number of activated caspase-3-positive cells, indicative of increased apoptotic cell death (b) compared to vehicle. This increase was potentiated when allopregnanolone synthesis was suppressed by finasteride treatment (c). Scale bar in $\mathbf{d}=100 \mu \mathrm{M}$.

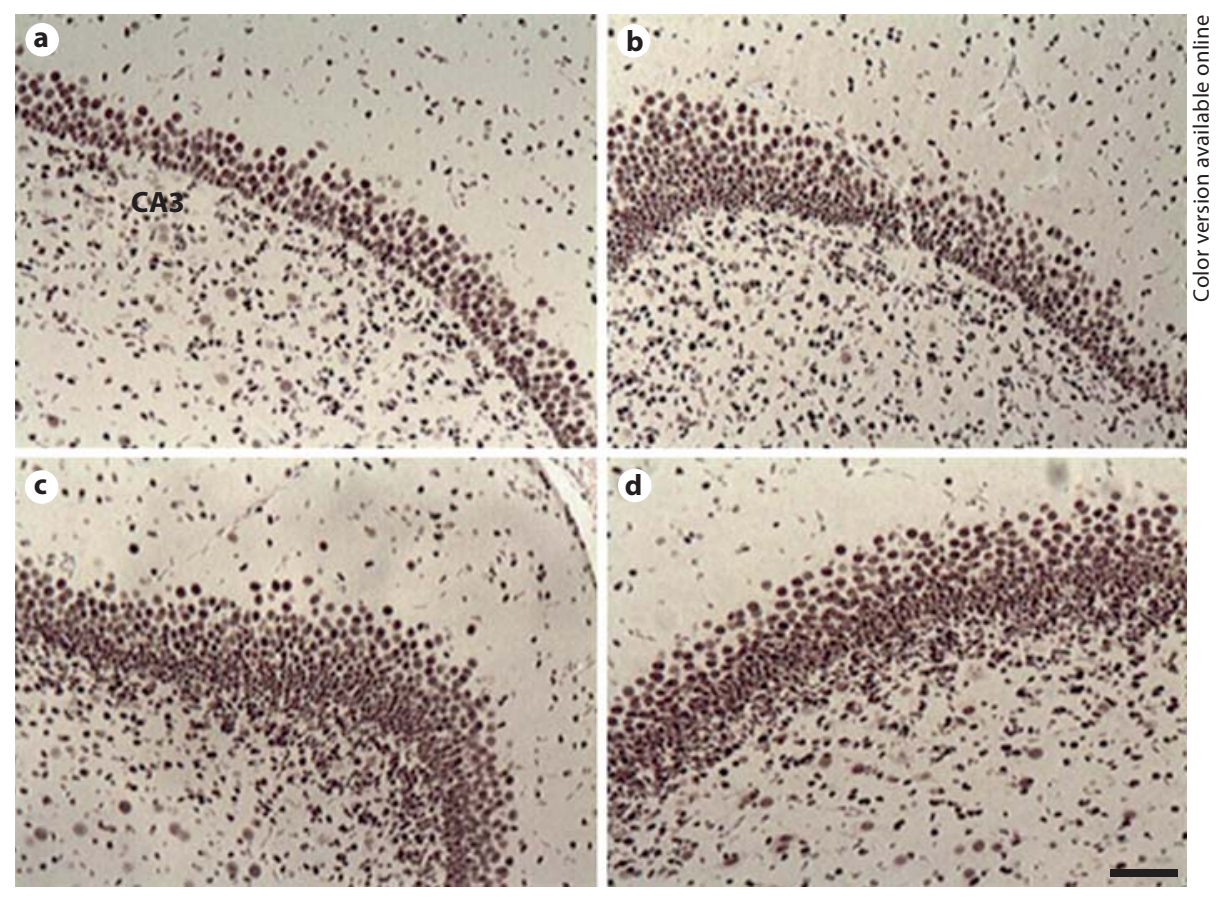

umbilical cord occlusion is consistent with a potentially protective role of pregnane steroids in these brain regions [Nguyen et al., 2004b].

To further investigate the role of allopregnanolone in protecting against brain cell death following acute hypoxia/ischemia in pregnancy, we determined the level of apoptotic cell death in the fetal sheep brain after a relatively mild episode of hypoxia/ischemia induced by occluding the umbilical cord for $5 \mathrm{~min}$. We then compared this to the amount of cell death after the allopregnanolone response had been blocked by $5 \alpha$-reductase inhibition with finasteride [Yawno et al., 2007b]. As shown in figure 5 , the $5 \mathrm{~min}$ of cord occlusion caused an increase in the number of activated caspase-3-positive cells, and this was potentiated when the allopregnanolone levels were suppressed by the finasteride treatment. This increase was most marked in the vulnerable CA1 and CA3 regions of the hippocampus (fig. 5), but this was also seen in areas of the cerebral cortex and cerebellum [Yawno et al., 2007b]. Interestingly, levels of activated caspase-3positive cells were somewhat elevated by finasteride treatment alone (fig. 5d). This observation is consistent with other studies which found that suppression of allopregnanolone synthesis increases basal level of apoptotic cell death in the fetal brain, an effect that was reversed by coadministration of the allopregnanolone analogue, alfaxalone [Yawno et al., 2009]. These results are consistent with our contention that the allopregnanolone response induced by acute hypoxia protects the brain from the full effects of hypoxia/ischemia. Also, it would appear that allopregnanolone is required to maintain normal levels of cell proliferation and cell death in the developing brain (see below). These results also raise the possibility of elevated levels of cell death and a greater risk of brain injury in the preterm neonate following the premature decline of neuroactive steroid levels in the brain as a consequence of the loss of the placenta.

\section{Neuroactive Steroid Responses to Hypoxic Stress after Birth}

The decline in allopregnanolone concentrations after birth results in concentrations markedly lower than in fetal life within $1 \mathrm{~h}$ of delivery [Nguyen et al., 2003b]. These lower levels then persist throughout the neonatal period, and may be necessary to allow increased levels of CNS activity, i.e., to support greater behavioral arousal. While this may also dispose the infant to a greater risk of seizures and excitotoxic brain injury, the brain of the normal-term neonate is also able to elicit neuroactive steroid responses. We examined the responses to stressors of hypoxia and lipopolysaccharide (LPS) exposure in newborn lambs [Billiards et al., 2006]. There was a sustained in- 
crease of plasma allopregnanolone concentrations for up to $6 \mathrm{~h}$ after LPS treatment, and a short response after a 30-min exposure to a hypoxic environment [Billiards et al., 2006]. The responses observed with hypoxia were consistent with those reported in adult rats that were subjected to hypercapnic stress [Barbaccia et al., 1996]. These findings show that responses similar to those seen in the adult are present from a young age. In further studies aimed at investigating responses to hypoxia in the presence of an underlying infection, we found that pretreatment with LPS markedly potentiated the allopregnanolone response to hypoxia [Billiards et al., 2006]. Human neonates can be delivered with serious sepsis as a result of intrauterine infections and then may become hypoxic in the immediate neonatal period due to ventilatory insufficiency. Our findings suggest that term neonates are able to rapidly increase synthesis of potentially protective neuroactive steroids in response to these stressors. In preliminary studies, we have observed marked $5 \alpha$-reductase expression in the adrenal glands of term fetal guinea pigs [unpubl. obs.]. This suggests that the adrenal glands may contribute neuroactive steroids or their precursors to the brain and this source could be particularly important after birth. But preterm neonates, particularly those born very preterm, are likely to have reduced adrenal function and this could reduce the availability of these essential steroid precursors to the brain. Further studies are required to determine the interaction between adrenal steroidogenesis with the brain and to determine if these potential interactions are reduced after preterm birth.

\section{Neuroactive Steroid Responses in Fetal Growth Restriction and Chronic Placental Insufficiency}

Disruption of placental function can cause chronic placental insufficiency and/or low placental perfusion, leading to intrauterine growth restriction (IUGR). Although not always associated with marked pathology at birth, IUGR can cause severe brain injury and even mild IUGR is correlated with subtle developmental abnormalities in later life. The impact of these complications on the developing brain is dependent upon the gestational age of the fetus at the time of injury and is also dependent on the time when the restriction becomes manifest [Inder and Volpe, 2000; Frisk et al., 2002; Luciana, 2003]. If placental function is reduced in early gestation, there is a relatively uniform reduction in body size. In contrast, limitation of placental function later in gestation results in asymmetrical growth restriction where the fetal head and brain are relatively less affected ('spared') compared to the body and somatic organs [Fang, 2005]. The latter is often the case with human fetal growth restriction and suggests that the brain may grow at a close to normal rate. However, the impact of placental compromise in maintaining neuroactive steroid levels in the fetal brain is an important question. To examine this, we have investigated the effects of severe and more moderate IUGR on neuroactive steroid production in two models of fetal growth restriction. We firstly examined the effect of a severe reduction of uterine blood supply in rats [Westcott et al., 2008]. In this model, one end of each of the uterine arteries was ligated to reduce the flow of maternal blood to each placenta. This chronic uterine hypoperfusion was sufficient to induce placental insufficiency and reduce fetal growth as well as reducing maternal plasma progesterone concentrations. Unexpectedly, allopregnanolone concentrations in the fetal brains at term were actually increased, rather than decreased. Given that GABAergic stimulation at this stage in development would increase excitation, this response might be expected to increase the risk of excitotoxic injury. However, these findings do suggest that chronic hypoxic fetal stress induces increased neuroactive steroid synthesis which may aid in stimulation of growth processes (see below), and perhaps is a response by cerebral tissues to compensate for the reduction in availability of pregnene precursors from the compromised placenta.

To further evaluate the effect of placenta insufficiency on neuroactive steroid concentration in the fetal brain and the potential impact on brain injury we established a model of a chronic long-term placental insufficiency [Nguyen et al., 2003a]. In this model, placental function was reduced by infusing microspheres into the fetal side of the placenta, reducing fetal placental blood flow and causing IUGR associated with a relatively mild, chronic fetal hypoxia. This was maintained by repeating the microsphere embolization each day, if necessary, for 20 days to keep fetal arterial oxygenation within the hypoxic range. The allopregnanolone concentration in the brain of these hypoxic fetal sheep was increased. These studies also showed that there was an increase in $5 \alpha$-reductase expression throughout the brain, suggesting that the rise in allopregnanolone resulted from the hypoxia-induced increase in the expression of this enzyme [Nguyen et al., 2003a]. This further suggests that even with a reduction in placental progesterone synthesis, there was sufficient precursor available to maintain and even increase neuroactive steroid production in the brain. 


\section{Neuroactive Steroid Replacement Strategies}

The hypoxic-induced increase in allopregnanolone concentration in the developing brain suggests that neuroactive steroids could play a role in the reduction of fetal activity, breathing, and energy demand that occur during hypoxia. These are the distinctive and characteristic responses of fetal and immature animals to hypoxia [Walker, 1995]. This concept is supported by our observation that when the production of this neuroactive steroid was blocked, fetal body movement was increased [Nicol et al., 2001]. Both IUGR and preterm neonates have greater susceptibility to seizure-type activity, including miniseizures which often go undetected in the clinical setting [Dean et al., 2005]. Premature loss of progesterone and its $\mathrm{GABA}_{\mathrm{A}}$ receptor agonist metabolites could contribute to the seizure susceptibility of the newborn. In the adult, $\mathrm{GABA}_{\mathrm{A}}$ receptor agonist neuroactive steroids such as ganaxalone have been shown to raise seizure threshold [Nohria and Giller, 2007], and replacement therapy with progesterone or a $5 \alpha$-reduced pregnane may improve neurological outcome in the 'at risk' neonate. For instance, seizure activity induced by picrotoxin treatment in fetal sheep could be blocked by allopregnanolone administration [Nicol et al., 1999]. Progesterone treatment has been found to have no adverse side effects on growth in preterm neonates [Trotter and Pohlandt, 2000], but potential effects on seizure activity and brain cell death were not evaluated in this study.

The finding that administration of progesterone or allopregnanolone have potent neuroprotective actions in adult models of hypoxia-ischemia brain injury [Bucolo and Drago, 2004] suggests that these steroids could be used in preterm neonates. The action of these steroids at the $\mathrm{GABA}_{\mathrm{A}}$ receptor results in post-synaptic hyperpolarization, with the overall effect on the brain reducing excitation. Examination of the sensitiveness of $\mathrm{GABA}_{\mathrm{A}}$ receptors to neuroactive steroid modulation indicates marked differences depending on subunit composition. This work further showed that a subunit composition typical of that seen in extrasynaptic receptors was most sensitive to neuroactive steroid activation. These observations suggest that neuroactive steroids exert most of their actions via interactions with extrasynaptic receptors rather than post-synaptic receptors [Belelli et al., 2002; Herd et al., 2008]. Furthermore, these findings indicate that neuroactive steroids reduce excitability largely by increasing tonic inhibition resulting from stimulation of extrasynaptic receptors [Stell et al., 2003; Mitchell et al., 2008]. While this suggests that neuroactive steroids exert global effects across several brain regions depending on their local concentration, it is more likely that differences in synthetic enzyme expression as well as receptor subunit composition lead to marked region-specific differences in the influence of neuroactive steroids in the brain [Mitchell et al., 2008].

Neuroactive steroids also reduce NMDA-induced excitotoxicity in both in vitro [Lockhart et al., 2002] and in vivo models of brain injury [Djebaili et al., 2005]. These excitatory pathways contribute to brain injury in the neonate following acute hypoxic episodes that may occur around the time of birth. In addition to being at risk of brain damage due to the chronic hypoxia alone, the IUGR fetus is also more susceptible to injury from acute hypoxia/ischemia-induced cell death at birth [Fang, 2005]. Studies show that greater damage is seen in vulnerable brain areas, such as the hippocampus, brainstem and cortex, when asphyxia is encountered by the already IUGR fetus. Burke et al. [2006] found that the dual insult of acute hypoxia in already IUGR fetuses resulted in a marked potentiation of expression of apoptotic marker in the brain of neonatal piglets. Similarly, IUGR human neonates that were exposed to a period of asphyxia due to placental infarction had increased brain injury [Burke and Gobe, 2005]. Enhanced excitation and increased vulnerability to brain damage suggest that these situations would be good targets for steroid-based neuroprotective therapies. Supplementation of neuroactive steroid concentrations at this time may attenuate brain damage in the neonate.

We have evaluated a neuroactive steroid therapy using the $\mathrm{GABA}_{\mathrm{A}}$ receptor agonist and sedative steroid alfaxalone in perinatal brain injury. IUGR was induced in the pregnant guinea pig fetus by ablation of about $50 \%$ of the branches of the uterine artery that supply each placenta. When this was done at mid-gestation, there was asymmetrical growth restriction resulting in an approximate $30 \%$ reduction in body weight and brain sparing, such that brain weight was not significantly reduced [Kelleher et al., 2007]. This treatment, however, created an enhanced sensitivity to apoptotic cell death when the fetuses were subjected to acute hypoxia/ischemia at birth. We observed greater activated caspase 3 expression in the CA1 region of the hippocampus when the fetuses were exposed to 3 min of hypoxia/ischemia at birth (fig. 6). This increase in apoptosis was attenuated by pretreating the dams with alfaxalone, $1 \mathrm{~h}$ before subjecting the fetuses to hypoxia/ ischemia at birth (fig. 6c). The dose of alfaxalone was less than that required to induce sedation of the dam, suggesting a selective, protective effect against the excessive excitation rather than an overall anesthetic action. Further 
Fig. 6. Photomicrograph showing activated caspase-3-immunoreactive cells in the hippocampus (CA1) of neonatal guinea pigs $24 \mathrm{~h}$ after birth. The neonates were delivered late in gestation by cesarean section. At the time of delivery the neonates were either delivered immediately (control) or subjected to asphyxia for $3 \mathrm{~min}$ (hypoxia). Prior to delivery $(1 \mathrm{~h})$ the mothers received either vehicle injection (vehicle) or alfaxalone injection (alfaxalone). The greatest number of activated caspase3 -positive cells were seen in the neonates from mothers that had received prebirth vehicle treatment and had been subjected to asphyxia. This was reduced with maternal prebirth alfaxalone administration. Scale bar $=120 \mu \mathrm{M}$.

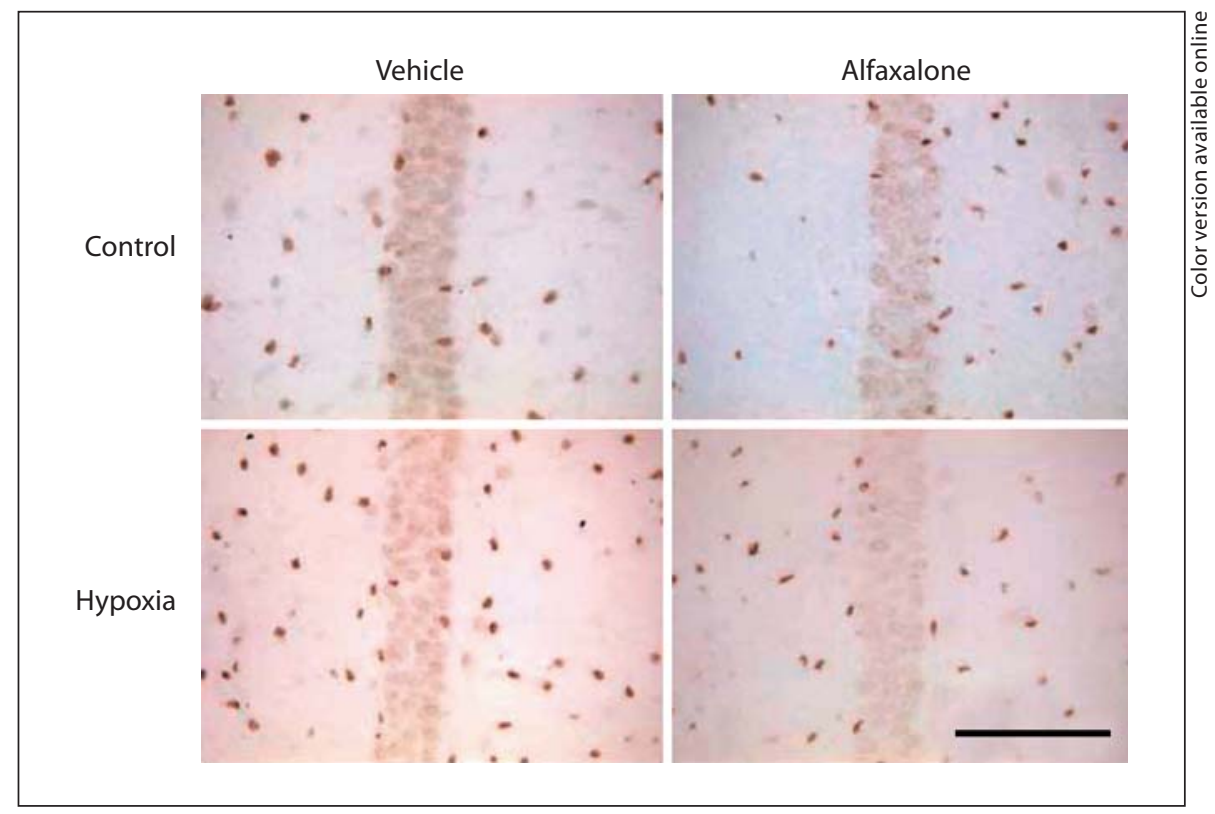

studies are required to determine if this type of treatment is effective after the asphyxia has occurred as this would be more relevant to the development of therapies for asphyxiated human newborns. In our studies, alfaxalone administration did not affect normal levels of apoptosis in the absence of the hypoxic/ischemic event (fig. 6), suggesting that short-term exposure to elevated neuroactive steroid levels does not influence normal cell turnover in the perinatal brain. However, given the effects of neuroactive steroids on growth (see below), further studies of the effects of longer-term exposure will be needed to delineate the safety of these potential therapies.

\section{Actions of Neuroactive Steroids on Growth and Repair}

Our studies in fetal sheep have shown that progesterone and its $5 \alpha$-reduced metabolites lower apoptotic cell death following acute injury [Nguyen et al., 2004b]. These steroids have also been found to reduce white matter damage following spinal cord contusion in rats [Thomas et al., 1999]. Although the exact mechanisms are not clear, these actions involve neuroactive steroid interaction with glial $\mathrm{GABA}_{\mathrm{A}}$ receptors. Oligodendrocytes possess marked $5 \alpha$-reductase expression and this may also account for some of the allopregnanolone present in the developing brain [Mellon et al., 2001]. We have also identified $5 \alpha$-reductase 2 expression in a population of cells in the subcortical white matter of the fetal sheep brain that also express an oligodendrocyte marker [Petratos et al., 2000]. These findings suggest that local neuroactive steroid synthesis may have a role in repair of white matter following damage, but may also affect the development of these regions. This suggestion is consistent with previous findings that neuroactive steroids stimulate myelination in the brain, and that this effect is mediated by GAB$A_{A}$ receptor stimulation [Ibanez et al., 2004]. The relatively high concentration of allopregnanolone during gestation may be important in these processes. Interestingly, we have shown that suppression of allopregnanolone levels with finasteride increased apoptotic cell death in the brain (fig. 4b) compared to controls. Furthermore, this treatment increased cell proliferation, particularly of astrocytes, changes that were reversed by co-infusion of the allopregnanolone analogue, alfaxalone [Yawno et al., 2007a]. These findings are consistent with a role for this neuroactive steroid in normal brain development during the weeks immediately before birth in long-gestation species, and the findings may therefore apply to human pregnancy.

\section{Progesterone in the Brain and PR Isoforms}

\section{Progesterone Action in the Developing Brain}

Neuroactive steroids have been identified as important regulators of brain development during the embry- 
onic period [Camacho-Arroyo et al., 2003, 2007]. Furthermore, progesterone has been suggested as potentially being an important neurotropic agent in the adult as well as in fetal brain [Brinton et al., 2008]. These observations suggest that progesterone may be an early mediator of development in specific brain regions as well as having a role in repair following brain injury caused by ischemic events [Brinton et al., 2008]. Although much of the placental progesterone production is metabolized on reaching the fetal circulation, the fetal brain is continuously exposed to unmetabolized progesterone albeit at lower concentrations than the maternal brain. In addition, the presence of P450scc in the fetal brain may augment concentrations by local synthesis; for example, cerebellar Purkinje cells produce progesterone. Thus, the fetal brain is likely to be exposed to significant levels of progesterone for most of gestation. This exposure appears to have a key influence on dendritic growth and synaptogenesis particularly in the cerebellum. Therefore, exposure to appropriate levels of progesterone may be crucial for normal brain development and organization in the second half of gestation.

\section{Mechanisms of Progesterone Action}

The neuroprotective roles of progesterone discussed so far require the metabolism of progesterone to pregnanes, with the $3 \alpha$-hydroxy metabolites being the most potent $\mathrm{GABA}_{\mathrm{A}}$ receptor agonists. Progesterone itself has little effect on either $\mathrm{GABA}_{\mathrm{A}}$ or NMDA receptors, but acts by the activation of intracellular PR in the brain [Brinton et al., 2008]. These PR contain a C-terminal ligand-binding domain for progesterone as well as a DNA binding site associated with a cluster of heat shock proteins that are released from the receptor in the presence of progesterone. Differences in the N-terminal of the PR result in the presence of $\mathrm{PR}$ isoforms. Two main isoforms of PR (PR-A and PR-B) are present in the brain and appear to have different regional and developmental expressions [Camacho-Arroyo et al., 2003]. A third splice variant has been identified (PR-C) and shown to have a limited expression in reproductive tissues, but there is no evidence of the expression of this isoform in the CNS [Mani, 2008].

PR expression has been measured during development, but with antibodies that measure total PR isoform expression. In the rat, from embryonic day 17 to postnatal day 28 , marked regional differences in total PR expression suggest potential functional differences in the role of progesterone during brain development [Quadros et al., 2007]. Progesterone has been found to stimulate neurotrophic genes, including brain-derived neurotrophic factor and growth-associated protein [Gonzalez Deniselle et al., 2007]. These studies suggest that progesterone has a potentially important role in promotion of cell growth, mediated by the PR [Gonzalez Deniselle et al., 2007]. Disruption in the expression of PR isoforms may contribute to adverse effects on growth, and appropriate placental progesterone synthesis may be necessary for normal fetal brain development.

Progesterone has been reported to stimulate myelination of neuronal cells, in vitro. The synthesis of progesterone by these cells has been suggested to drive myelination in associated Schwann cells by acting on PR [Chan et al., 2000]. Stimulation of myelination has also been proposed to lead to the progesterone-induced reduction of the white matter damage following spinal cord injury in rats [Thomas et al., 1999]. Oligodendrocytes express both P450scc and 3 $\beta$-hydroxysteroid dehydrogenase, and are likely to produce a high local concentration of progesterone which may stimulate myelination in the CNS [Zwain and Yen, 1999], although it is not clear if this is mediated via a PR-dependent pathway [Ibanez et al., 2004]. These studies support a role for progesterone in increasing myelination after injury and suggest these processes may be potentially important when normal myelination has been retarded. In preliminary studies in guinea pigs, immunohistochemical analysis of myelin basic protein expression, a marker of myelination, was used to evaluate the effect of an in utero stress. Myelination was reduced in the hippocampal CA1 region and cortex of late-gestation IUGR-affected fetuses and 1-dayold neonates from these pregnancies [unpubl. obs.]. Human infants from IUGR pregnancies also have a tendency for reduced myelination and connectivity [Geva et al., 2006].

Progesterone has been found to act on gene expression in neural cells to promote myelination by interaction with associated Schwann cells. As PR were not detectable in Schwann cells, these observations suggest an interaction between neuronal and glial cells to promote myelination [Schumacher et al., 2007]. This response was blocked by treatment with the PR antagonist, RU486, indicating that the effect was mediated by PR [Gago et al., 2001; Schumacher et al., 2007]. These observations, and the increasing expression of PR throughout the rat brain with advancing developmental age, support the contention that these receptors have a key role in progesterone-mediated stimulation of myelination. However, these studies only examined total PR expression and changes in the relative expression of PR isoforms are also likely to be important. 
In reproductive tissues, $\mathrm{PR}-\mathrm{B}$ is a dominant mediator of progesterone action whereas the $\mathrm{N}$-terminal truncated isoform, PR-A, suppresses the actions of PR-B [Vegeto et al., 1993]. Therefore, it is the ratio of isoform expression that is important in these tissues with an increase in the $\mathrm{PR}-\mathrm{A}: \mathrm{PR}-\mathrm{B}$ ratio reducing progesterone action. In the fetal and neonatal guinea pig brain, both PR-A and PR-B isoforms were present in the hippocampus and cerebellum. However, PR-B expression was considerably lower than PR-A in the cerebellum and was very low in the hippocampus [Yates et al., 2009]. If regulation of PR action is similar in the CNS as in reproductive tissues, this high PR-A:PR-B ratio would limit progesterone action in the developing brain. Interestingly, the PR-A:PR-B ratio was decreased in IUGR fetal guinea pigs suggesting that progesterone may have a more marked action on the brain in compromised pregnancies [Yates et al., 2009]. Further studies are required to elucidate the role of changes in the PR-A:PR-B ratio in myelination in normal and IUGR pregnancies.

\section{Conclusions}

Pregnancy is characterized by elevated neuroactive steroid levels both in the maternal circulation and brain as well as, importantly, in the fetal brain. These steroids have a major role in influencing fetal CNS activity in late gestation and contribute to the high incidence of sleeplike behavioral states that typifies fetal life. Stressors in pregnancy place the fetus at risk of brain injury which, if serious, can cause major neurological impairment, whereas less severe insults can cause cognitive and behavioral problems in later life. The fetus is able to respond to hypoxic challenges by raising neuroactive steroid production, leading to elevated concentrations, particularly of the potent $\mathrm{GABA}_{\mathrm{A}}$ receptor agonist allopregnanolone, in the brain. Inhibition of allopregnanolone synthesis markedly enhances brain cell death following acute hypoxia/ischemia. This may represent the situation of the preterm newborn and thus contribute to their vulnerability to hypoxic/ischemic insults. $5 \alpha$-Reductases appear to have a key regulatory role in fetal allopregnanolone production and the expression of these enzymes rises in response to stress; however, the supply of precursors from the placenta, and possibly the fetal adrenal glands, is required to maintain allopregnanolone concentrations in the developing brain. In addition, $5 \alpha$-reductases in the placenta may contribute baseline neuroactive steroid levels to the brain which are augmented by local metabolism of precursors. The loss of the placenta at birth leads to a dramatic fall in allopregnanolone levels in the neonate's brain and increases vulnerability to hypoxic stress. Recent findings suggest that the normally high fetal neuroactive steroid levels are also required to maintain the developmentally appropriate level of cell death and glial proliferation in the fetal brain. Furthermore, neuroactive steroid action via the $\mathrm{GABA}_{\mathrm{A}}$ receptor, and progesterone action via $\mathrm{PR}$, appear to have an important role in promoting myelination as term approaches. Together, these observations suggest that the premature loss of the placenta following preterm birth may adversely affect neonatal development and increase vulnerability of the brain to injury. This vulnerability may be even greater in the IUGR fetus which is likely to already have compromised growth trajectories.

\section{Acknowledgements}

This project was supported by a grant from the National Health \& Medical Research Council of Australia to J.J.H. and D.W.W.

\section{References}

Back SA, Han BH, Luo NL, Chricton CA, Xanthoudakis S, Tam J, Arvin KL, Holtzman DM (2002): Selective vulnerability of late oligodendrocyte progenitors to hypoxiaischemia. J Neurosci 22:455-463.

- Barbaccia ML, Roscetti G, Trabucchi M, Mostallino MC, Concas A, Purdy RH, Biggio G (1996): Time-dependent changes in rat brain neuroactive steroid concentrations and GABA receptor function after acute stress. Neuroendocrinol 63:166-172.
Baulieu EE (1997): Neurosteroids: of the nervous system, by the nervous system, for the nervous system. Recent Prog Horm Res 52:132.

-Belelli D, Casula A, Ling A, Lambert JJ (2002): The influence of subunit composition on the interaction of neurosteroids with GABA(A) receptors. Neuropharmacology 43:651-661.

\footnotetext{
Belelli D, Herd MB, Mitchell EA, Peden DR, Vardy AW, Gentet L, Lambert JJ (2006): Neuroactive steroids and inhibitory neurotransmission: mechanisms of action and physiological relevance. Neuroscience 138: 821-829.

Bicikova M, Klak J, Hill M, Zizka Z, Hampl R, Calda P (2002): Two neuroactive steroids in midpregnancy as measured in maternal and fetal sera and in amniotic fluid. Steroids 67: 399-402.
} 
Billiards S, Nguyen PN, Canny BJ, Walker DW, Hirst JJ (2006): Hypoxia and endotoxin interact to regulate sleep and allopregnanolone concentrations in the newborn lambs. Biol Neonate 90:258-267.

-Bixo M, Andersson A, Winblad B, Purdy RH, Backstrom T (1997): Progesterone, $5 \alpha$ pregnane-3,20-dione and $3 \alpha$-hydroxy-5 $\alpha$-pregnane-20-one in specific regions of the human female brain in different endocrine states. Brain Res 764:173-178.

Bloch M, Daly RC, Rubinow DR (2003): Endocrine factors in the etiology of postpartum depression. Compr Psychiatry 44:234-246.

Brinton RD, Thompson RF, Foy MR, Baudry M, Wang J, Finch CE, Morgan TE, Pike CJ, Mack WJ, Stanczyk FZ, Nilsen J (2008): Progesterone receptors: form and function in brain. Front Neuroendocrinol 29:313339.

Bucolo C, Drago F (2004): Effects of neurosteroids on ischemia-reperfusion injury in the rat retina: role of sigmal recognition sites. Eur J Pharmacol 498:111-114.

Burke C, Gobe G (2005): Pontosubicular apoptosis ('necrosis') in human neonates with intrauterine growth retardation and placental infarction. Virchows Arch 446:640645.

- Burke C, Sinclair K, Cowin G, Rose S, Pat B, Gobe G, Colditz P (2006): Intrauterine growth restriction due to uteroplacental vascular insufficiency leads to increased hypoxia-induced cerebral apoptosis in newborn piglets. Brain Res 1098:19-25.

-Camacho-Arroyo I, Gonzalez-Arenas A, Gonzalez-Aguero G, Guerra-Araiza C, GonzalezMoran G (2003): Changes in the content of progesterone receptor isoforms and estrogen receptor alpha in the chick brain during embryonic development. Comp Biochem Physiol A Mol Integr Physiol 136:447-452.

Camacho-Arroyo I, Hernandez-Molina VI, Rivas-Suarez M, Guerra-Araiza C, GonzalezMoran MG (2007): Changes in progesterone receptor isoforms content in the brain of immature, mature and aged male and female chickens. Gen Comp Endocrinol 150:381385.

Castillo-Melendez M, Chow JA, Walker DW (2004): Lipid peroxidation, caspase- 3 immunoreactivity, and pyknosis in late-gestation fetal sheep brain after umbilical cord occlusion. Pediatr Res 55:864-871.

Chan JR, Rodriguez-Waitkus PM, Ng BK, Liang P, Glaser M (2000): Progesterone synthesized by Schwann cells during myelin formation regulates neuronal gene expression. Mol Biol Cell 11:2283-2295.

Clewlow F, Dawes GS, Johnston BM, Walker DW (1983): Changes in breathing, electrocortical and muscle activity in unanaesthetized fetal lambs with age. J Physiol 341:463-476.

Conley AJ, Mason JI (1990): Placental steroid hormones. Baillieres Clin Endocrinol Metab 4:249-272.
Crossley KJ, Nicol MB, Hirst JJ, Walker DW, Thorburn GD (1997): Suppression of arousal by progesterone in fetal sheep. Reprod Fertil Dev 9:767-773.

Crossley KJ, Walker DW, Beart PM, Hirst JJ (2000): Characterisation of GABA(A) receptors in fetal, neonatal and adult ovine brain: region and age related changes and the effects of allopregnanolone. Neuropharmacology 39:1514-1522.

Dean J, George S, Wassink G, Gunn A, Bennet L (2005): Suppression of post-hypoxic-ischemic EEG transients with dizocilpine is associated with partial striatal protection in the preterm fetal sheep. Neuropharmacology 50:491-503.

Djebaili M, Guo Q, Pettus EH, Hoffman SW, Stein DG (2005): The neurosteroids progesterone and allopregnanolone reduce cell death, gliosis, and functional deficits after traumatic brain injury in rats. J Neurotrauma 22:106-118.

Dolling M, Seamark RF (1979): Progestagen metabolites in fetal sheep plasma: the effect of fetal nephrectomy. J Dev Physiol 1:399413.

du Plessis AJ, Volpe JJ (2002): Perinatal brain injury in the preterm and term newborn. Curr Opin Neurol 15:151-157.

Fang S (2005): Management of preterm infants with intrauterine growth restriction. Early Hum Dev 81:889-900.

Frisk V, Amsel R, Whyte HE (2002): The importance of head growth patterns in predicting the cognitive abilities and literacy skills of small-for-gestational-age children. Dev Neuropsychol 22:565-593.

Gago N, Akwa Y, Sananes N, Guennoun R, Baulieu EE, El-Etr M, Schumacher M (2001): Progesterone and the oligodendroglial lineage: stage-dependent biosynthesis and metabolism. Glia 36:295-308.

Geva R, Eshel R, Leitner Y, Fattal-Valevski A, Harel S (2006): Memory functions of children born with asymmetric intrauterine growth restriction. Brain Res 1117:186-194.

Gilbert Evans SE, Ross LE, Sellers EM, Purdy RH, Romach MK (2005): $3 \alpha$-Reduced neuroactive steroids and their precursors during pregnancy and the postpartum period. Gynecol Endocrinol 21:268-279.

Gonzalez Deniselle MC, Garay L, Gonzalez S, Saravia F, Labombarda F, Guennoun R, Schumacher M, De Nicola AF (2007): Progesterone modulates brain-derived neurotrophic factor and choline acetyltransferase in degenerating Wobbler motoneurons. Exp Neurol 203:406-414.

-Harris B, Lovett L, Smith J, Read G, Walker R, Newcombe R (1996): Cardiff puerperal mood and hormone study. 3. Postnatal depression at 5 to 6 weeks postpartum, and its hormonal correlates across the peripartum period. Br J Psychiatry 168:739-744.
Harrison NL, Majewska MD, Harrington JW, Barker JL (1987): Structure-activity relationships for steroid interaction with the gamma-aminobutyric acid A receptor complex. J Pharmacol Exp Ther 241:346-353.

- Herd MB, Haythornthwaite AR, Rosahl TW, Wafford KA, Homanics GE, Lambert JJ, Belelli D (2008): The expression of GABAA beta subunit isoforms in synaptic and extrasynaptic receptor populations of mouse dentate gyrus granule cells. J Physiol 586:9891004.

Hill M, Cibula D, Havlikova H, Kancheva L, Fait T, Kancheva R, Parizek A, Starka L (2007): Circulating levels of pregnanolone isomers during the third trimester of human pregnancy. J Steroid Biochem Mol Biol 105:166175.

Ibanez C, Shields SA, El-Etr M, Baulieu EE, Schumacher M, Franklin RJ (2004): Systemic progesterone administration results in a partial reversal of the age-associated decline in CNS remyelination following toxin-induced demyelination in male rats. Neuropathol Appl Neurobiol 30:80-89.

-Inder TE, Huppi PS, Warfield S, Kikinis R, Zientara GP, Barnes PD, Jolesz F, Volpe JJ (1999): Periventricular white matter injury in the premature infant is followed by reduced cerebral cortical gray matter volume at term. Ann Neurol 46:755-760.

Inder TE, Volpe JJ (2000): Mechanisms of perinatal brain injury. Semin Neonatol 5:3-16.

Kelleher M, Palliser H, Yates D, Sullivan R, Walker D, Hirst J (2007): Effect of inhibition of 5alpha-reduced steroid synthesis on apoptotic brain cell death and neurosteroidogenic enzyme expression in the fetal and neonatal guinea pig. Reprod Sci 15:102.

Kellogg CK (1988): Benzodiazepines: influence on the developing brain. Prog Brain Res 73: 207-228.

Liere P, Pianos A, Eychenne B, Cambourg A, Liu S, Griffiths W, Schumacher M, Sjovall J, Baulieu E-E (2004): Novel lipoidal derivatives of pregnenolone and dehydroepiandrosterone and absence of their sulfated counterparts in rodent brain. J Lipid Res 45:2287-2302.

Lockhart EM, Warner DS, Pearlstein RD, Penning DH, Mehrabani S, Boustany RM (2002): Allopregnanolone attenuates N-methyl-Daspartate-induced excitotoxicity and apoptosis in the human NT2 cell line in culture. Neurosci Lett 328:33-36.

Luciana M (2003): Cognitive development in children born preterm: implications for theories of brain plasticity following early injury. Dev Psychopathol 15:1017-1047.

Mani S (2008): Progestin receptor subtypes in the brain: the known and the unknown. Endocrinology 149:2750-2756.

-Martini L, Celotti F, Melcangi RC (1996): Testosterone and progesterone metabolism in the central nervous system: cellular localization and mechanism of control of the enzymes involved. Cell Mol Neurobiol 16:271-282. 
McKay (1987): Mechanisms involved in the control of steroidogenesis during the oestrous cycle and pregnancy in sheep; $\mathrm{PhD}$ thesis Monash University, Melbourne.

McLean C, Ferriero D (2004): Mechanisms of hypoxic-ischemic injury in the term infant. Semin Perinatol 28:425-432.

- Mellon SH, Griffin LD, Compagnone NA (2001): Biosynthesis and action of neurosteroids. Brain Res Brain Res Rev 37:3-12.

-Milewich L, Gant NF, Schwarz BE, Chen GT, MacDonald PC (1979): $5 \alpha$-Reductase activity in human placenta. Am J Obstet Gynecol 133:611-617.

Milewich L, Kaimal V, Johnson AR (1987): Steroid $5 \alpha$-reductase activity in endothelial cells from human umbilical cord vessels. J Steroid Biochem 26:561-567.

Mitchell EA, Herd MB, Gunn BG, Lambert JJ, Belelli D (2008): Neurosteroid modulation of GABAA receptors: molecular determinants and significance in health and disease. Neurochem Int 52:588-595.

- Nappi RE, Petraglia F, Luisi S, Polatti F, Farina C, Genazzani AR (2001): Serum allopregnanolone in women with postpartum 'Blues'. Obstet Gynecol 97:77-80.

- Nguyen PN, Billiards SS, Walker DW, Hirst JJ (2003a): Changes in $5 \alpha$-pregnane steroids and neurosteroidogenic enzyme expression in fetal sheep with umbilicoplacental embolization. Pediatr Res 54:840-847.

- Nguyen PN, Billiards SS, Walker DW, Hirst JJ (2003b): Changes in 5 $\alpha$-pregnane steroids and neurosteroidogenic enzyme expression in the perinatal sheep. Pediatr Res 53:956964.

- Nguyen PN, Ross Young I, Walker DW, Hirst JJ (2004a): Allopregnanolone in the brain and blood after disruption of the hypothalamicpituitary-adrenal axis in fetal sheep. J Endocrinol 182:81-88.

- Nguyen PN, Yan EB, Castillo-Melendez M, Walker DW, Hirst JJ (2004b): Increased allopregnanolone levels in the fetal sheep brain following umbilical cord occlusion. J Physiol 560:593-602.

Nicol MB, Hirst JJ, Walker DW (1998): Effect of pregnane steroids on electrocortical activity and somatosensory evoked potentials in fetal sheep. Neurosci Lett 253:111-114.

Nicol MB, Hirst JJ, Walker DW (1999): Effects of pregnanolone on behavioural parameters and the responses to GABAA receptor antagonists in the late gestation fetal sheep. Neuropharmacology 38:49-63.
Nicol MB, Hirst JJ, Walker DW (2001): Effect of finasteride on behavioural arousal and somatosensory evoked potentials in fetal sheep. Neurosci Lett 306:13-16.

Nohria V, Giller E (2007): Ganaxolone. Neurotherapeutics 4:102-105.

-Paoletti AM, Romagnino S, Contu R, Orru MM, Marotto MF, Zedda P, Lello S, Biggio G, Concas A, Melis GB (2006): Observational study on the stability of the psychological status during normal pregnancy and increased blood levels of neuroactive steroids with GABA-A receptor agonist activity. Psychoneuroendocrinology 31:485-492.

Petratos S, Hirst JJ, Mendis S, Anikijenko P, Walker DW (2000): Localization of p450scc and $5 \alpha$-reductase type- 2 in the cerebellum of fetal and newborn sheep. Brain Res Dev Brain Res 123:81-86.

Quadros PS, Pfau JL, Wagner CK (2007): Distribution of progesterone receptor immunoreactivity in the fetal and neonatal rat forebrain. J Comp Neurol 504:42-56.

Richardson BS (1992): The effect of behavioral state on fetal metabolism and blood flow circulation. Semin Perinatol 16:227-233.

-Saunders NR, Knott GW, Dziegielewska KM (2000): Barriers in the immature brain. Cell Mol Neurobiol 20:29-40.

Schumacher M, Guennoun R, Stein DG, De Nicola AF (2007): Progesterone: therapeutic opportunities for neuroprotection and myelin repair. Pharmacol Ther 116:77-106.

- Schumacher M, Liere P, Akwa Y, Rajkowski K, Griffiths W, Bodin K, Sjovall J, Baulieu E-E (2008): Pregnenolone sulfate in the brain: a controversial neurosteroid. Neurochem Int 52:522-540

-Sheehan PM, Rice GE, Moses EK, Brennecke SP (2005): $5 \beta$-Dihydroprogesterone and steroid 5beta-reductase decrease in association with human parturition at term. Mol Hum Reprod 11:495-501.

Smith R (2007): Parturition. N Engl J Med 356: 271-283.

Stein DG (2008): Progesterone exerts neuroprotective effects after brain injury. Brain Res Rev 57:386-397.

- Stell BM, Brickley SG, Tang CY, Farrant M, Mody I (2003): Neuroactive steroids reduce neuronal excitability by selectively enhancing tonic inhibition mediated by delta subunit-containing GABAA receptors. Proc Natl Acad Sci USA 100:14439-14444.

- Szeto HH (1992): Behavioral states and their ontogeny: animal studies. Semin Perinatol 16: 211-216.

- Thomas AJ, Nockels RP, Pan HQ, Shaffrey CI, Chopp M (1999): Progesterone is neuroprotective after acute experimental spinal cord trauma in rats. Spine 24:2134-2138.
Trotter A, Pohlandt F (2000): The replacement of oestradiol and progesterone in very premature infants. Ann Med 32:608-614.

-Vegeto E, Shahbaz MM, Wen DX, Goldman ME, O’Malley BW, McDonnell DP (1993): Human progesterone receptor a form is a celland promoter-specific repressor of human progesterone receptor B function. Mol Endocrinol 7:1244-1255.

- Vu TT, Hirst JJ, Stark M, Wright IMR, Palliser HK, Hodyl N, Clifton VL (2009): Changes in human placental 5alpha-reductase isoenzyme expression with advancing gestation: effects of fetal sex and glucocorticoid exposure. Reprod Fertil Dev 21:599-607.

-Walker DW (1995): Hypoxic inhibition of breathing and motor activity in the foetus and newborn. Clin Exp Pharmacol Physiol 22:533-536

-Weaver CE Jr, Wu FS, Gibbs TT, Farb DH (1998): Pregnenolone sulfate exacerbates NMDAinduced death of hippocampal neurons. Brain Res 803:129-136.

-Westcott KT, Hirst JJ, Ciurej I, Walker DW, Wlodek ME (2008): Brain allopregnanolone in the fetal and postnatal rat in response to uteroplacental insufficiency. Neuroendocrinology 88:287-292.

- Yan E, Castillo-Melendez M, Nicholls T, Hirst J, Walker D (2004): Cerebrovascular responses in the fetal sheep brain to low-dose endotoxin. Pediatr Res 55:855-863.

Yates D, Hirst JJ, Palliser HK (2009): Effect of IUGR and sex on functional PR expression in the fetal guinea pig. J Paediatr Child Health 45:A124.

Yawno T, Castillo-Melendez M, Hirst J, Walker D (2007a): Neuroprotective role of allopregnanolone for cerebellar Purkinje cells in fetal sheep. IBRO 7th World Congr Neurosci Program, Melbourne, POS-337.

Yawno T, Hirst JJ, Castillo-Melendez M, Walker DW (2009): Protective role of neurosteroids in the late gestation fetal sheep. 5th Int Meet Steroids Nervous System, Torino.

- Yawno T, Yan EB, Walker DW, Hirst JJ (2007b): Inhibition of neurosteroid synthesis increases asphyxia-induced brain injury in the late gestation fetal sheep. Neuroscience 146: 1726-1733.

Zwain IH, Yen SS (1999): Neurosteroidogenesis in astrocytes, oligodendrocytes, and neurons of cerebral cortex of rat brain. Endocrinology 140:3843-3852. 